\title{
Irminger Current Anticyclones in the Labrador Sea observed in the hydrographic record, 1990-2004
}

\author{
by Tatiana Rykova ${ }^{1}$, Fiammetta Straneo ${ }^{2}$, Jonathan M. Lilly ${ }^{3}$ and Igor Yashayaev ${ }^{4}$
}

\begin{abstract}
A significant fraction of the lateral heat transport into the Labrador Sea's interior, needed to balance the net heat loss to the atmosphere, is attributed to the Irminger Current Anticyclones. These mesoscale eddies advect warm, salty boundary current water, of subtropical origin, from the boundary current to the interior-but when or how they release their anomalous heat content has not been previously investigated. In this study, we discuss the seasonal and interannual evolution of these anticyclones as inferred from the analysis of hydrographic data from the Labrador Sea from 1990 to 2004. The 29 identified anticyclones fall into two categories, which we refer to as unconvected and convected. Unconvected anticyclones have properties that are close to those of the boundary current, including a fresh surface layer, and they are found near the boundaries and never observed in winter. Convected anticyclones, on the other hand, contain a mixed layer, lack a freshwater cap and are observed throughout the year. Using a one-dimensional mixing model, it is shown that the convected eddies are those Irminger Current Anticyclones that have been modified by the large winter buoyancy loss of the region. This provides evidence that such eddies can survive the strong winter buoyancy loss in the Labrador Sea and that their anomalous heat and salt content is not trivially mixed into the Sea's interior. Finally, we observe a clear trend in the eddies' properties toward warmer and saltier conditions after 1997 reflecting changes in the source waters and the reduced atmospheric forcing over the Labrador Sea.
\end{abstract}

\section{Introduction}

The Labrador Sea is an important contributor to the Meridional Overturning Circulation and a key location for the global heat and freshwater balance (LabSea Group, 1998; Straneo, 2006a; Schmidt and Send, 2007; Dickson et al., 2007). Intermediate convection here results in the formation of Labrador Sea Water (LSW), one of the components of North Atlantic Deep Water (LabSea Group, 1998; Marshall and Schott, 1999; Haine et al., 2007). Convection is primarily driven by the large wintertime heat loss (Dickson et al., 1996) and tends to be confined to the western part of the central Labrador Sea (Lazier,

1. Department of Earth, Planetary and Atmospheric Sciences, M.I.T., Cambridge, Massachusetts, 02139, U.S.A.email: tata@mit.edu

2. Department of Physical Oceanography, Woods Hole Oceanographic Institution, Woods Hole, Massachusetts, U.S.A., 02543.

3. Earth and Space Research, 2101 Fourth Avenue, Seattle, Washington, 98121, U.S.A.

4. Bedford Institute of Oceanography, Halifax, NS B3B, Canada. 


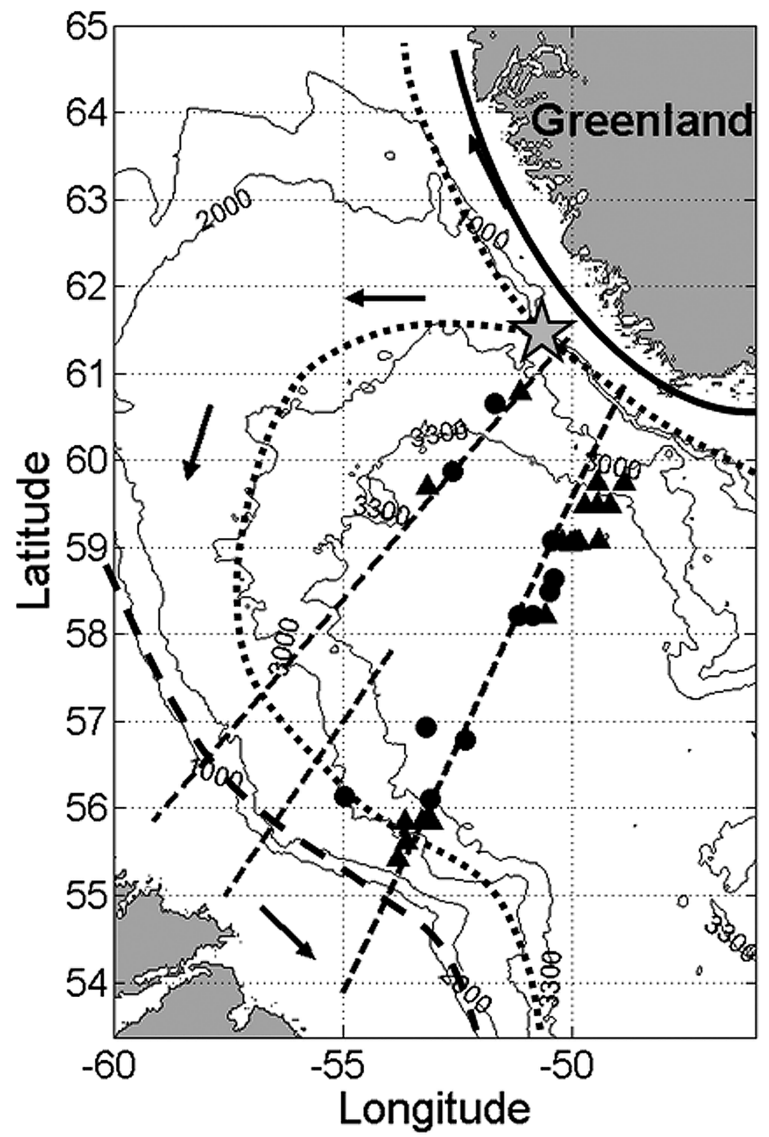

Figure 1. Schematic circulation of the Labrador Sea overlaid on the bathymetry (thin black lines with numbers indicating the depths of 1000, 2000, 3000 and $3300 \mathrm{~m}$ ). The southernmost section (AR7W) and the other two sections occupied are shown by the thin dashed lines. The West Greenland Current (WGC) is shown by a solid line, the Irminger Current (IC) by a thick dotted line, and the Labrador Current is shown by a thick dashed line. Arrows represent the direction of the flow. The star marks the approximate location of eddy formation. Symbols indicate the locations where the ICAs were found. Convected ICAs are identified by circles and unconvected ICAs by triangles.

1980; LabSea Group, 1998; Pickart et al., 2002). This central region is encircled by a boundary current system, flowing around the basin's perimeter (Fig. 1), which transports both fresh, cold surface waters of Arctic origin and warm, salty subsurface waters of subtropical origin (Cuny et al., 2002; Pickart et al., 2002).

The large wintertime heat loss to the atmosphere that occurs over the basin is balanced by the net influx of warm subtropical waters transported by the boundary current. Over the mostly quiescent interior (Lavender et al., 2000), the surface heat loss is balanced by a net 
convergence of heat via lateral eddy fluxes (Lilly et al., 1999; Straneo, 2006a). These fluxes are thought to result from two instability pathways: baroclinic instability distributed around the basin (Spall, 2004; Straneo, 2006b), and localized topographic instability of the boundary current (Eden and Böning, 2002; Katsman et al., 2004; Bracco et al., 2008). They drive the post-convection restratification of the interior, through the advection of fresh surface waters and warm, salty subsurface waters from the boundary current (Straneo, 2006a; Lazier et al., 2002; Lilly et al., 2003, hereafter L03), and remove the convective product from the interior (Katsman et al., 2004; Spall, 2004; Straneo, 2006b).

One special type of eddy, the Irminger Current Anticyclone (ICA) or Irminger Ring, is thought to play a particularly important role in the advection of heat into the central region. These eddies contain a thick, subsurface layer of warm Irminger Water-modified subtropical water carried around the basin in the boundary current and its extension (e.g. Cuny et al., 2002), and are thought to contribute between 25 to $100 \%$ of the heat needed to balance the surface heat loss (L03; Katsman et al., 2004; Hatun et al., 2007, hereafter H07). They are formed off the west coast of Greenland in a region characterized by a change in topographic slope (Katsman et al., 2004; Bracco et al., 2008) and a large sea-surface height variability and eddy kinetic energy (Prater, 2002; L03; Lavender et al., 2005). A recent study found that several of these eddies had a fresh, surface layer and suggested that they may also play an important role in the freshwater cycle through the Labrador Sea's interior (H07).

Even while recognized as important to the Labrador Sea's heat and freshwater cycles, little is know about the fate of these eddies. In particular, it is unclear if their anomalous heat and freshwater content is released slowly via mixing and eddy decay or if, for example, they are destroyed by the strong wintertime air-sea fluxes which characterize this region. Furthermore, it is unclear how their characteristics may change interannually and to what extent they contribute to the hydrographic variability observed in the Labrador Sea. Indeed, it has been found that only part of the Sea's large interannual variability can be attributed to the atmospheric forcing (Dickson et al., 1996; Pickart et al., 2002; L03) while the rest is attributed to changes in the lateral fluxes (L03 and Straneo, 2006a). Since the degree of restratification has an impact on convection in the years to follow, there is a growing interest in identifying and understanding the mechanisms which control it.

The present study aims to improve our understanding of ICAs by analyzing a large hydrographic data set collected in the Labrador Sea from 1990 to 2004 to identify ICAs. By mapping seasonal and interannual changes in their properties and locations we seek to quantify the anomalous heat and freshwater content of the eddies and understand how these vary through an eddy's life-cycle. One particular focus of this study is to document the transformation which the ICAs undergo in the winter, when the Labrador Sea is subject to a large surface buoyancy loss. Can the eddies survive these wintertime fluxes? If so, how are they transformed?

This paper begins with a review of what is known about ICAs from previous studies. These studies provide us with a number of criteria for the detection of ICAs from 
hydrographic data. The general characteristics of the ICAs identified in this study are described in section 3, together with their classification within one of two groups: unconvected and convected ICAs. Property analysis and a one-dimensional mixing model are used in section 4 to argue that the latter group are indeed ICAs which have been transformed by the wintertime fluxes of the Labrador Sea. The interannual variations within the ICAs are described in section 5, including how changes in their properties compare with those of the Labrador Sea interior. A summary and discussion of the findings of this study are presented in section 6 .

\section{Background: Characteristics of the eddies}

Previous studies have identified three kinds of eddies that populate the Labrador Sea: convectively formed anticyclones, Irminger Current Cyclones and Anticyclones (Lilly et al., 2002; L03; H07). This work focuses on the Irminger Current Anticyclones (ICAs), the most noticeable contributor to the Labrador Sea's heat and freshwater budgets. These have been studied from a variety of data sources which include moorings, floats, altimetry and gliders and their characteristics are described in Prater (2002), who identified one ICA from profiling RAFOS floats; L03, who examined thirteen ICAs from a 1994-1999 mooring record and sea surface height (SSH) anomalies in the satellite along track data altogether; and H07, who studied three ICAs using Seagliders and a variety of satellite products. The basic findings of these studies are briefly reviewed here.

To orient the reader we present the schematic of the region in Figure 1. The Labrador Sea is located in the northwest corner of the North Atlantic between Greenland and the Labrador coast of Canada. The current system around the region is comprised of several branches. The surface branch consists of the cold and fresh West Greenland Current on the Greenland side and Labrador Current on the Labrador side of the basin. Beneath and offshore these currents, the Irminger Current carries warm, salty water around the basin (Cuny et al., 2002).

ICAs are formed from an instability of the West Greenland/Irminger Current system off the west Greenland coast, at the location of the change in the topographic slope (Prater, 2002 and L03; Fig.1). This region, which is associated with a maximum in eddy kinetic energy (EKE), is important for the exchange of properties between the interior and the boundary current (Straneo et al., 2003). Tracking of individual, large-amplitude, isolated sea-surface height anomalies from the EKE maximum to a mooring in the central Labrador Sea-where these anomalies were found to be associated with subsurface $\theta / \mathrm{S}$ properties typical of ICAs-allowed L03 to identify this region as the ICA generation region. Eddy generation is thought to peak in winter (December to March) when both sea-surface height variance (Prater, 2002) and eddy kinetic energy (L03) peak.

ICAs are characterized by a thicker and more pronounced layer of warm, salty Irminger Water than the Labrador Sea's interior (Prater, 2002 and L03) or than the neighboring water masses in the current (H07). This is consistent with the general notion that at formation, these eddies trap warm and salty Irminger Water (IW) from the boundary 
current and preserve its properties by inhibiting lateral mixing. Properties of the eddies' warm and salty cores are observed to vary: potential temperature $\theta=4.9^{\circ} \mathrm{C}$ in Prater's eddy, $\theta \approx 3-4.15^{\circ} \mathrm{C}$ and $S \approx 34.85$ in L03's eddies, while $\theta \approx 4.6-5.2^{\circ} \mathrm{C}$ and $S \approx$ 34.9 in H07's eddies. It is unclear if this variability reflects differences at formation or transformation following formation. The eddies' core radii have been estimated to be $25 \mathrm{~km}$ (Prater, 2002), 15-30 km (L03) and 30-35 km (H07). Their anticyclonic circulation is supported both by the trajectories of Prater's RAFOS floats, by their positive SSH anomaly and agreement of the moored current meter record with a model eddy, and finally by the direct velocity measurements by the glider. The estimated azimuthal velocities are 20-40 $\mathrm{cm} \mathrm{s}^{-1}$ (Prater, 2002), 30-80 $\mathrm{cm} \mathrm{s}^{-1}$ (L03) and 50-70 $\mathrm{cm} \mathrm{s}^{-1}$ (H07).

One important additional feature described by $\mathrm{H} 07$ is that the ICAs have a fresh and cold surface layer of approximately $200 \mathrm{~m}\left(\theta \approx 2.5^{\circ} \mathrm{C}\right.$ and $\left.S \approx 34.3\right)$. This is consistent with the boundary current structure to the west of Greenland where cold, fresh waters of Arctic origin are found to lay above, and onshore of, the warm, salty Irminger Water (see for example Lazier et al., 2002). At present, it is unclear whether the fresh surface cap was only a feature of the $\mathrm{H} 07$ eddies or if such a cap might also have been present in the eddies observed by Prater, 2002, and L03 who (1) perhaps documented eddies already modified by the surface fluxes at the time of the observation implying that the freshwater cap had been removed if it existed and (2) were unable to fully resolve the upper part of the water column and would not have been able to detect it in all their measurements.

Two different pathways for eddy propagation from their formation region have been identified: (1) slow southwest drift towards the central Labrador Sea (L03); (2) relatively fast advection within the branch of the Irminger Current which veers off the Greenland slope following the $3000 \mathrm{~m}$ isobath (Prater, 2002; H07, Fig. 1). Eddies following the first pathway reach the central Labrador Sea in approximately 2 months, at an average translation speed of $5 \mathrm{~cm} \mathrm{~s}^{-1}$ - consistent with the expansion of the EKE maximum toward this region (L03 and Prater, 2002). The second pathway was confirmed by the glider observations that detected three eddies trapped within the westward flowing Irminger Current branch. It is unclear from that study, however, where and if the ICAs leave the boundary current to drift into the basin's interior.

\section{ICAs in the hydrographic data}

\section{a. Data}

This study utilizes hydrographic data collected in the Labrador Sea from 1990 to 2004. It contains data along the AR7W World Ocean Circulation Experiment (WOCE) line (mostly occupied by the Bedford Institute of Oceanography but also by other groups). Additionally we included a 1998 section collected by E. D'Asaro during the Labrador Sea Deep Convection Experiment (LabSea Group, 1998). Most of the 33 sections in this data set were sampled along the AR7W line but several sections included data collected along slightly different lines (Fig. 1). These data, or portions thereof, have been used and 
described in a number of studies including Lazier et al. (2002), L03, Pickart and Spall (2007), Rhein et al. (2007), and Yashayaev et al. (2007a, b). Most of the sections were occupied in the late spring or summer with the exception of the wintertime sections of 1997 and 1998 and the fall sections of 1996 and 2002.

\section{b. Criteria for finding the ICAs}

In this study, ICAs are identified from hydrographic data based on the characteristics described above. Specifically, we rely on the fact that at formation the eddy's properties are similar to those of the Irminger Water found in the current along west Greenland and that they retain this subsurface warm, salty anomaly as they drift into the Labrador Sea's interior (Fig. 2). Thus, we identify ICAs by seeking warm, salty and buoyant anomalies in the 200-1000 m depth range, the Irminger Water depth range, in hydrographic stations outside of the boundary currents. We require at least one profile separating the boundary current from the prospective eddy profile to avoid describing meanders. Because the properties of both the boundary current and the interior vary considerably both seasonally and interannually (Yashayaev et al., 2007a), it does not make sense to look for absolute properties in the Irminger Water density/depth range. Instead, we look for warm $\left(>0.1^{\circ} \mathrm{C}\right)$ and salty $(>0.01)$ anomalies that space at least $100 \mathrm{~m}$ in the $200-1000 \mathrm{~m}$ depth range in the individual hydrographic profiles (after a 50-m low pass filter) with respect to a mean interior profile. The mean interior profile is defined as the spatial average of the temperature and salinity profiles within the $3300 \mathrm{~m}$ isobath (the same definition of interior used by L03, Yashayaev et al., 2003 and Straneo, 2006a). Note that potential eddy profiles are subjectively omitted when estimating the mean interior conditions. Potential eddies are further visually inspected to ensure that their structure indeed resembles what we expect ICAs to look like, based on earlier studies.

It is noted that these criteria are quite stringent and thus, as shown below, there is little doubt that the anomalies identified are indeed ICAs. More likely, the stringency of the criteria eliminated potential ICAs which were sampled at their edge or were weak enough (for example due to erosion) that their characteristics were no longer truly distinguishable from filaments or decaying coherent eddies. Finally, we note that from the hydrographic data alone it is impossible to establish if an eddy was sampled near its center or on its flank. The studies of $\mathrm{H07}$ and L03, however, show that properties within the eddy are fairly homogeneous over the roughly $30 \mathrm{~km}$ core of the eddy and that the gradients are confined to the narrow eddy boundary of about $7 \mathrm{~km}$. Thus, their findings support the notion that ICAs have a relatively homogeneous core which can be captured by one or two profiles.

\section{c. Eddy characteristics}

Using the criteria described above, we found 29 ICAs in the hydrographic data whose basic characteristics (including location and time/date when observed) are listed in Table 1. The second column represents the type of eddy as described further in the text: uICA is "unconvected" and cICA is "convected" anticyclones. The core potential temperature and 

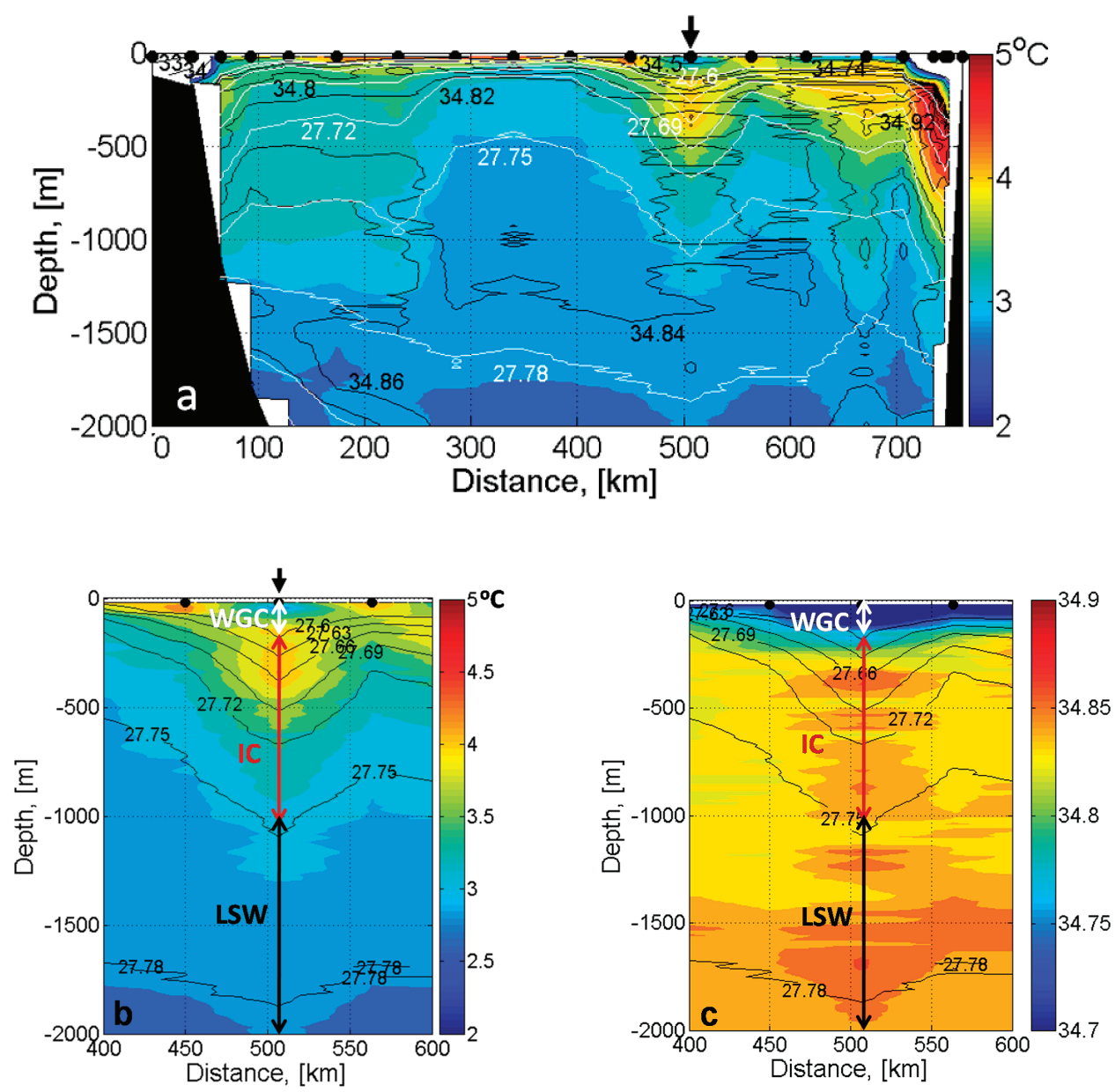

Figure 2. (a) A hydrographic section of potential temperature $\theta$ (color), salinity (black contours) and potential density $\sigma_{\theta}$ (white contours) across the Labrador Sea sampled in May 1997. The arrow marks the location of an ICA. (b) Potential temperature and (c) salinity in the ICA (May 1997) with arrows indicating different water masses and black dots representing positions of the hydrographic stations.

salinity are defined as the properties associated with the subsurface salinity maximum in the IW range in the eddy profile. (Note that the subsurface temperature and salinity maxima are slightly offset both in eddies and in the boundary current with the temperature maximum typically being slightly closer to the surface than the salinity one).

Overall, the eddies were distributed throughout most of the area occupied by the hydrographic sections (Fig. 1). Their temperature and salinity anomalies with respect to the interior's mean are shown in Figures $3 \mathrm{a}$ and $3 \mathrm{~b}$. As evident from these figures, these features are characterized by sizable anomalies in the Irminger Water depth range. The $\theta / S$ 
Table 1. Properties of the unconvected (uICAs) and convected (cICAs) eddies. The cICAs belonging to different clusters are indicated by I and II (see text for clarifications).

\begin{tabular}{|c|c|c|c|c|c|c|c|}
\hline Number & $\begin{array}{c}\text { Type of } \\
\text { ICA }\end{array}$ & Longitude & Latitude & Year & Month & Eddy Core $S$ & Eddy Core $\theta$ \\
\hline 1 & uICA & -49.44 & 59.49 & 1990 & 7 & 34.90 & 3.96 \\
\hline 2 & uICA & -53.37 & 55.78 & 1993 & 6 & 34.91 & 4.21 \\
\hline 3 & uICA & -53.11 & 55.97 & 1993 & 6 & 34.90 & 4.28 \\
\hline 4 & uICA & -49.94 & 59.06 & 1993 & 6 & 34.87 & 3.62 \\
\hline 5 & uICA & -53.39 & 55.84 & 1993 & 6 & 34.90 & 4.21 \\
\hline 6 & uICA & -49.47 & 59.45 & 1993 & 6 & 34.87 & 3.61 \\
\hline 7 & uICA & -49.16 & 59.75 & 1994 & 5 & 34.88 & 3.80 \\
\hline 8 & uICA & -53.82 & 55.42 & 1994 & 6 & 34.88 & 3.70 \\
\hline 9 & uICA & -49.95 & 59.06 & 1995 & 6 & 34.86 & 3.51 \\
\hline 10 & uICA & -50.88 & 58.22 & 1996 & 5 & 34.86 & 3.32 \\
\hline 11 & uICA & -49.95 & 59.06 & 1996 & 5 & 34.85 & 3.21 \\
\hline 12 & uICA & -53.63 & 55.61 & 1996 & 10 & 34.87 & 3.44 \\
\hline 13 & $\operatorname{cICA}(\mathrm{I})$ & -52.34 & 56.78 & 1996 & 11 & 34.85 & 4.49 \\
\hline 14 & $\operatorname{cICA}(\mathrm{I})$ & -52.61 & 59.88 & 1997 & 2 & 34.89 & 4.02 \\
\hline 15 & $\operatorname{cICA}(\mathrm{I})$ & -51.70 & 60.65 & 1997 & 2 & 34.90 & 4.31 \\
\hline 16 & cICA (II) & -54.97 & 56.13 & 1997 & 2 & 34.86 & 3.35 \\
\hline 17 & cICA (II) & -50.87 & 58.22 & 1997 & 3 & 34.83 & 3.38 \\
\hline 18 & uICA & -53.17 & 60.78 & 1997 & 5 & 34.86 & 4.23 \\
\hline 19 & uICA & -51.15 & 59.75 & 1997 & 6 & 34.88 & 4.15 \\
\hline 20 & cICA (II) & -53.11 & 56.11 & 1998 & 2 & 34.84 & 3.65 \\
\hline 21 & cICA (II) & -53.20 & 56.94 & 1998 & 2 & 34.84 & 3.59 \\
\hline 22 & $\operatorname{cICA}(\mathrm{I})$ & -50.88 & 58.22 & 1998 & 2 & 34.88 & 4.05 \\
\hline 23 & $\operatorname{cICA}(\mathrm{I})$ & -50.41 & 58.64 & 1998 & 7 & 34.85 & 4.31 \\
\hline 24 & uICA & -49.17 & 59.75 & 1999 & 7 & 34.91 & 4.58 \\
\hline 25 & uICA & -49.47 & 59.49 & 2001 & 6 & 34.89 & 4.13 \\
\hline 26 & uICA & -49.93 & 59.07 & 2002 & 7 & 34.89 & 4.12 \\
\hline 27 & uICA & -49.47 & 59.84 & 2002 & 7 & 34.89 & 4.13 \\
\hline 28 & $\operatorname{cICA}(\mathrm{I})$ & -49.94 & 59.07 & 2002 & 12 & 34.87 & 4.85 \\
\hline 29 & $\operatorname{cICA}(\mathrm{I})$ & -50.51 & 58.50 & 2004 & 5 & 34.89 & 4.31 \\
\hline
\end{tabular}

characteristics of these ICAs fall between those of the interior of the Labrador Sea and those of the boundary current on the Greenland side (Fig. 3c). One apparent characteristic of the ICAs is that they are associated with a temperature maximum and a salinity maximum resulting in an "elbow" in $\theta / S$ space (Fig. 3) in the Irminger Water range, $\sigma_{\theta}=$ $27.65-27.72 \mathrm{~kg} \mathrm{~m}^{-3}$ range (Pickart et al., 2002). All the ICAs identified in this study exhibited the characteristic "elbow."

The ICAs identified fall naturally into two groups which we refer to as unconvected and convected for reasons that will appear clear shortly. Of the 29 ICAs, 18 were of the unconvected kind while 11 of the convected kind. The properties of the unconvected eddies (uICAs) are quite similar to those of the boundary current, with a fresh (and sometimes cold) layer at the surface and a warm and salty layer at mid-depth. An example of an uICA 

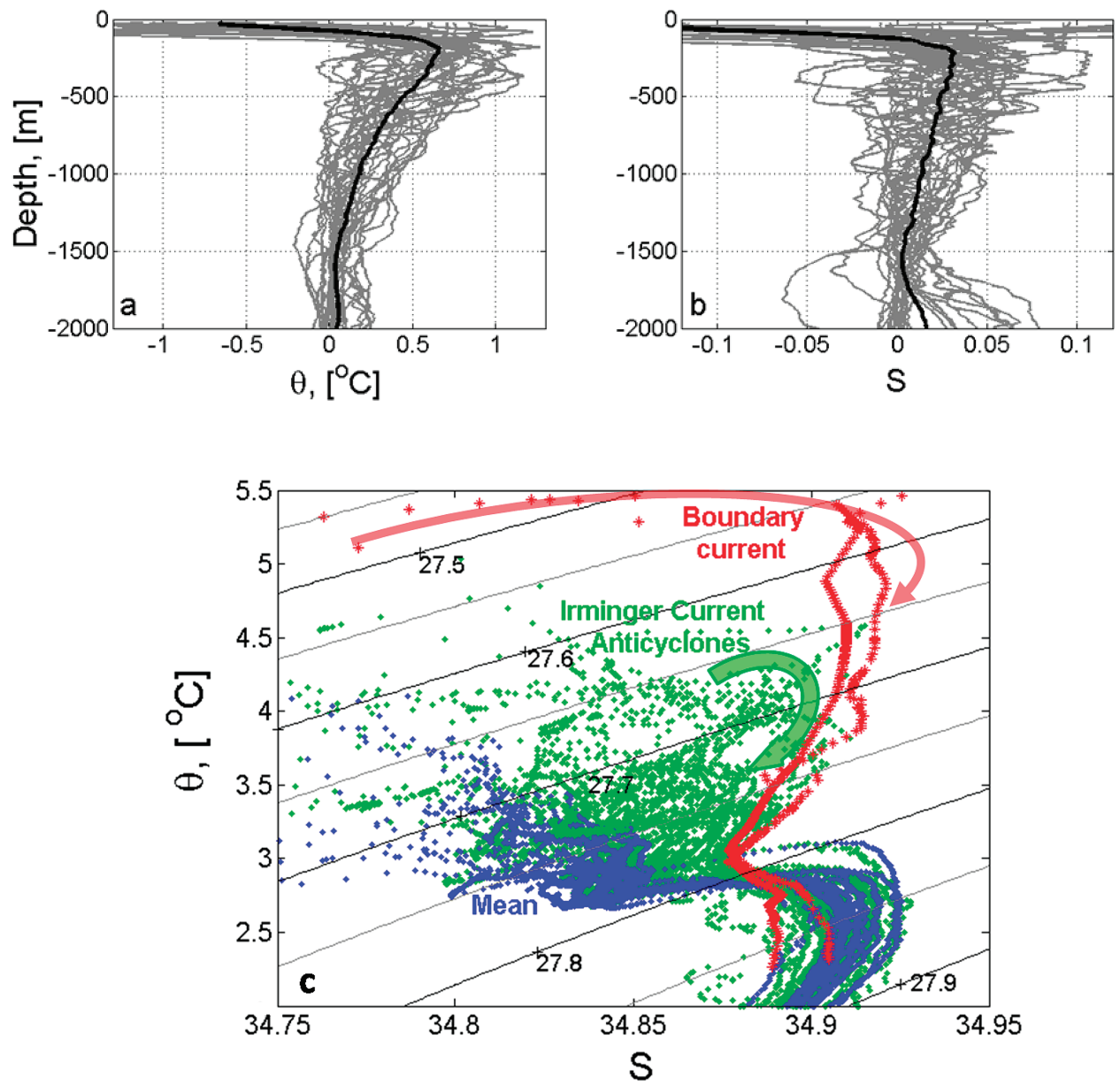

Figure 3. Characteristics of the ICAs: (a) potential temperature and (b) salinity anomalies (gray) for all ICAs relative to the interior (see text); the average anomaly is shown in black; (c) $\theta / S$ diagram for ICAs (green), Labrador Sea interior (blue) and two typical profiles from the West Greenland Current (red). The arrow indicates schematically the elbow in $\theta / \mathrm{S}$ space associated with the ICAs.

is shown in Figure 4. All the panels display the hydrographic properties of the eddy compared to the properties of the boundary current and mean section profiles. The seasonal distribution is such that no uICAs were found in the winter sections.

Convected eddies (cICAs, Fig. 5) are defined as those containing at least one mixed layer whose thickness exceeds $100 \mathrm{~m}$ and within which temperature and salinity are homogeneous. The mixed layers observed were up to $800 \mathrm{~m}$ thick and not necessarily located at the surface. This is consistent with what was first documented by L03 who argue that these deep mixed layers have convective origin and speculated that they had subducted underneath the lighter waters leading to vertical stacking of mixed layers. One important 

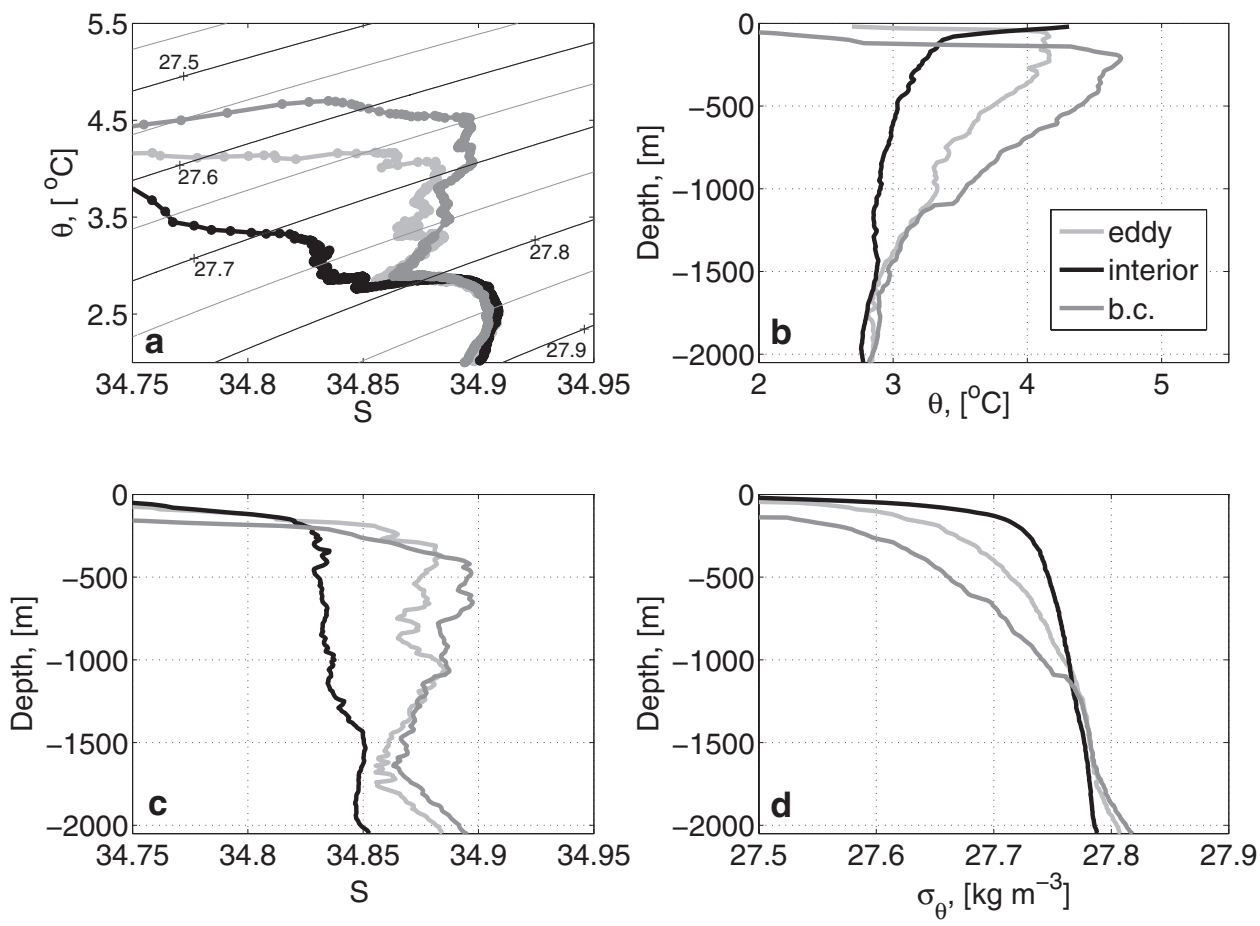

Figure 4. (a) $\theta / S$ diagram; (b) potential temperature; (c) salinity; and (d) potential density for the unconvected eddy observed in spring of 1997 (gray), the interior (black), and the boundary current (dark gray).

finding of this study, whose possible causes and implications are discussed later, is that none of the cICAs have a fresh surface layer. Also, while cICAs were observed in all seasons, they were only found after the winter of 1996-1997.

It is reasonable to assume that the vertical mixed layer is evidence that the convected ICAs have endured at least one winter since formation and that the large wintertime surface buoyancy loss has resulted in a partial homogenization of properties within the eddy followed, in some cases, by surface restratification. This is supported both by the fact that the cICAs contain at least one vertically mixed layer and, in general, that their stratification, in the surface and intermediate depth water masses $\left(\sigma=27.64-27.73 \mathrm{~kg} \mathrm{~m}^{-3}\right)$ is lower than that observed in the uICAs (Fig. 6). The weak stratification is consistent with the fact that the water column is vertically mixed from the surface down during convection. Similarly, the absence of a fresh surface cap, in the cICAs, is also consistent with wintertime convection since this would rapidly lead to the mixing of salty water into the surface mixed layer (as happens in the central Labrador Sea, (Straneo, 2006a). Further evidence that this class of ICAs has undergone wintertime transformation is provided by the fact that all of the (seven) ICAs observed in winter were cICAs (i.e. contain mixed 

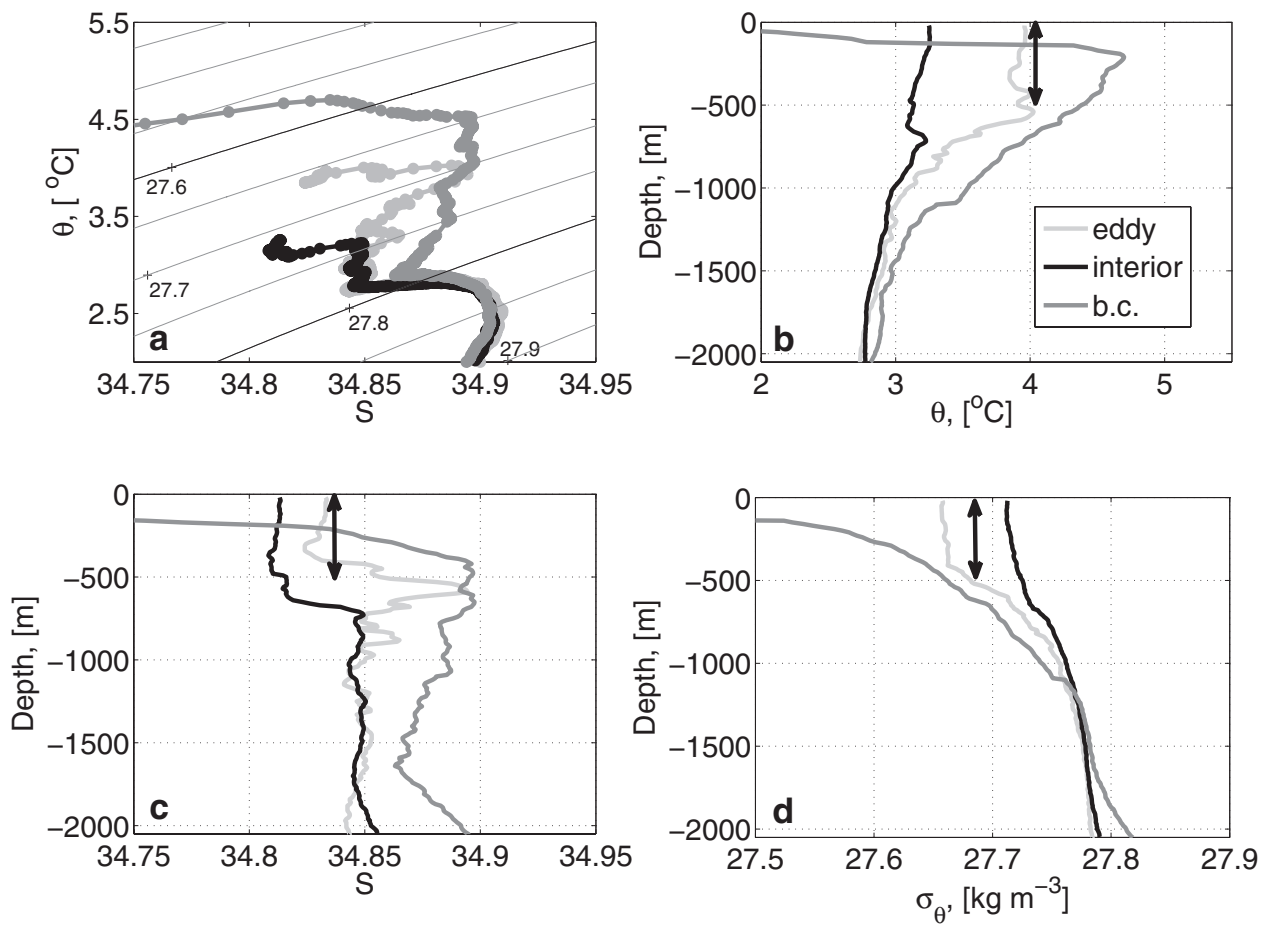

Figure 5. A convected eddy observed in winter of 1997. (a) $\theta / S$ diagram; (b) potential temperature; (c) salinity; (d) potential density in the eddy (gray), interior (black) and boundary current (b. c., dark gray). The mixed layer in the eddy is indicated with an arrow.

layers and had no freshwater cap). Likely these eddies were still undergoing transformation while observed. Both eddies observed in the late fall contain a shallow mixed layer (they are also labeled as cICAs); likely they have just started experiencing convection. Finally, the two mixed layers observed in one summer ICA may indicate an eddy which may have survived two winters or, perhaps, merging of two convectively modified eddies (as proposed by L03). A more in depth analysis of convection in ICAs is given in the next section.

\section{d. Spatial distribution}

The uICAs are found mostly clustered in the proximity of the boundary currents on both the Greenland and Labrador sides of the basin, and only a few are found in the interior, while cICAs are typically found only in the central Labrador Sea (Fig. 1). The cluster off the Greenland coast is consistent with the interior eddy pathway (1) described above. These eddies were all observed in the late spring/summer and assuming a drift speed of roughly $5 \mathrm{~cm} \mathrm{~s}^{-1}$ (L03), it would have taken them about 30 to 70 days to reach the locations where they are found. This finding is consistent with their formation during winter (the peak formation period) and their subsequent drifting toward the central Labrador Sea. 


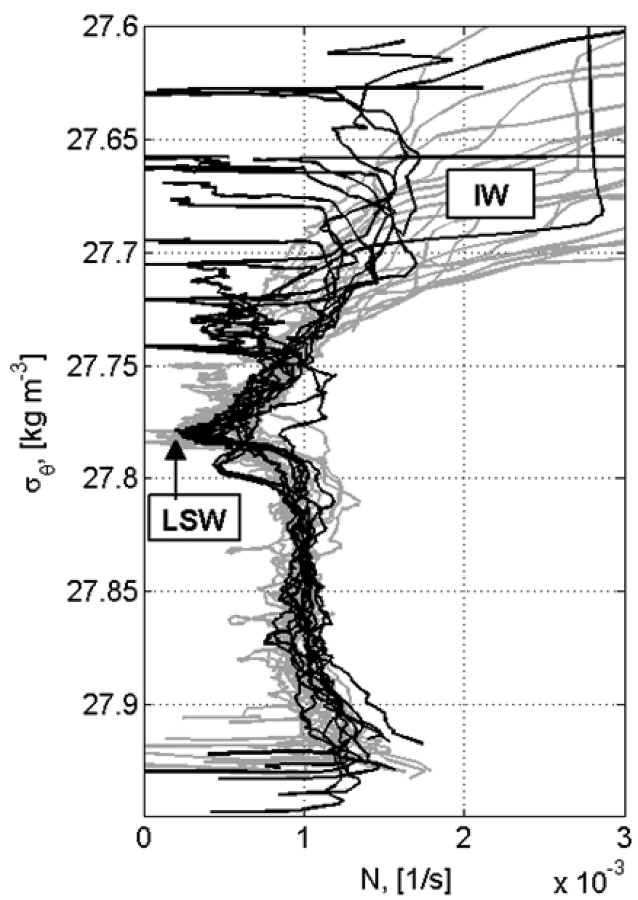

Figure 6. Buoyancy period in convected (black) and unconvected (gray) ICAs as a function of potential density. Boxes indicate approximate location of Irminger Water (IW) and Labrador Sea Water (LSW) in the ICAs (see text for the definition).

Regarding the uICAs observed in the cluster off the Labrador coast (see Fig. 1), if they had reached their location by traversing the central Labrador Sea it would have taken them roughly four months, assuming the inferred mean interior drift speed of $5 \mathrm{~cm} \mathrm{~s}^{-1}$. If, on the other hand, these eddies had taken the "rapid route" around the Labrador Sea, pathway (2) described above, in the westward extension of the current which follows the $3000 \mathrm{~m}$ isobath, then their travel time is likely to have been only on the order of two months, assuming speeds in the range of $12-20 \mathrm{~cm} \mathrm{~s}^{-1}$ (Lavender et al., 2000 and Cuny et al., 2002). Since these eddies were observed in June, it seems unlikely that they could have been formed four months earlier without showing any indication of convective modification. Indeed they contain the freshest surface waters and warmest Irminger Water observed in any ICAs ( $\mathrm{S} \approx 33.6-33.9$ at the surface; $\theta \approx 3.96-4.21^{\circ} \mathrm{C}$ in the IW range) suggesting, if anything, that they have undergone little modification since formation. This finding supports the existence of a second pathway for ICAs to propagate into the Labrador Sea's interior. This pathway may provide a rapid, and sizable, input of both heat and fresh water from the west Greenland side to the Labrador Sea's western interior through eddy advection within the current and, eventually, eddy drift into the interior. 

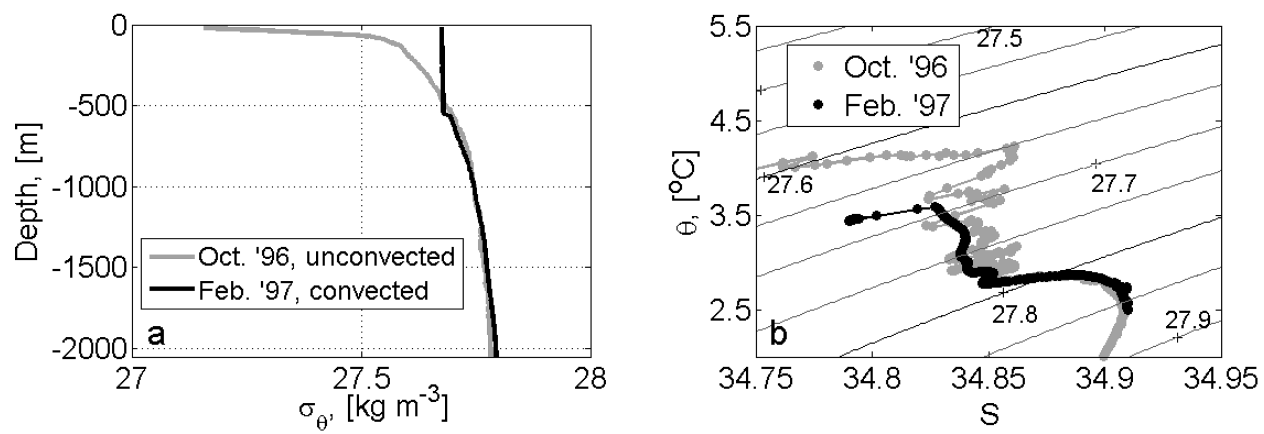

Figure 7. Potential density (left) and $\theta / S$ diagram (right) of a convected (Feb. 1997) and an unconvected (Oct. 1996) ICA.

\section{Wintertime modification of an ICA}

We have identified two types of eddies in the Labrador Sea which we claim to be convected and unconvected ICAs. Here we present evidence that supports the conclusion that cICAs are simply uICAs which have experienced at least one Labrador Sea winter and have undergone convective modification. We show this both qualitatively as well as quantitatively by predicting the evolution of the mixed layer properties in an uICA when subjected to a realistic surface buoyancy loss.

The first circumstantial evidence that cICAs are convectively transformed uICAs is shown in Figure 7, where an unconvected eddy observed in October 1996 is compared to a convected eddy from February 1997. Note that these eddies are sampled at different locations so these profiles could belong to the same eddy that moved south between October 1996 and February 1997, or to different eddies. The density profile of the winter eddy is consistent with convective mixing to about $500 \mathrm{~m}$, beyond which the properties of the two eddies are very similar.

We use a mixed layer model to show that the properties of the mixed layers within the cICAs are what one would expect to observe if uICAs were subjected to a realistic surface buoyancy loss. In using a one-dimensional model we are assuming that the large wintertime buoyancy loss drives mostly vertical mixing (as in the Labrador Sea's interior, Harcourt et al., 2002). In addition, it is likely that the coherent nature of the eddies impedes strong lateral mixing during restratification-again supporting the vertical mixing assumption. To investigate the evolution of uICAs during the winter of the Labrador Sea we use the one-dimensional model described in Lilly et al. (1999) and L03. This model takes an initial profile, a given surface buoyancy flux, and predicts the evolution of both the mixed layer depth and its properties. Model assumptions are that (1) the mixed layer is vertically homogeneous, (2) properties below the mixed layer depth are unchanged with respect to the initial profile and (3) density at the base of the mixed layer is continuous, i.e. the model represents non-penetrative convective mixing (though both potential temperature and salinity can be discontinuous at the base). The thermal expansion and haline contraction 


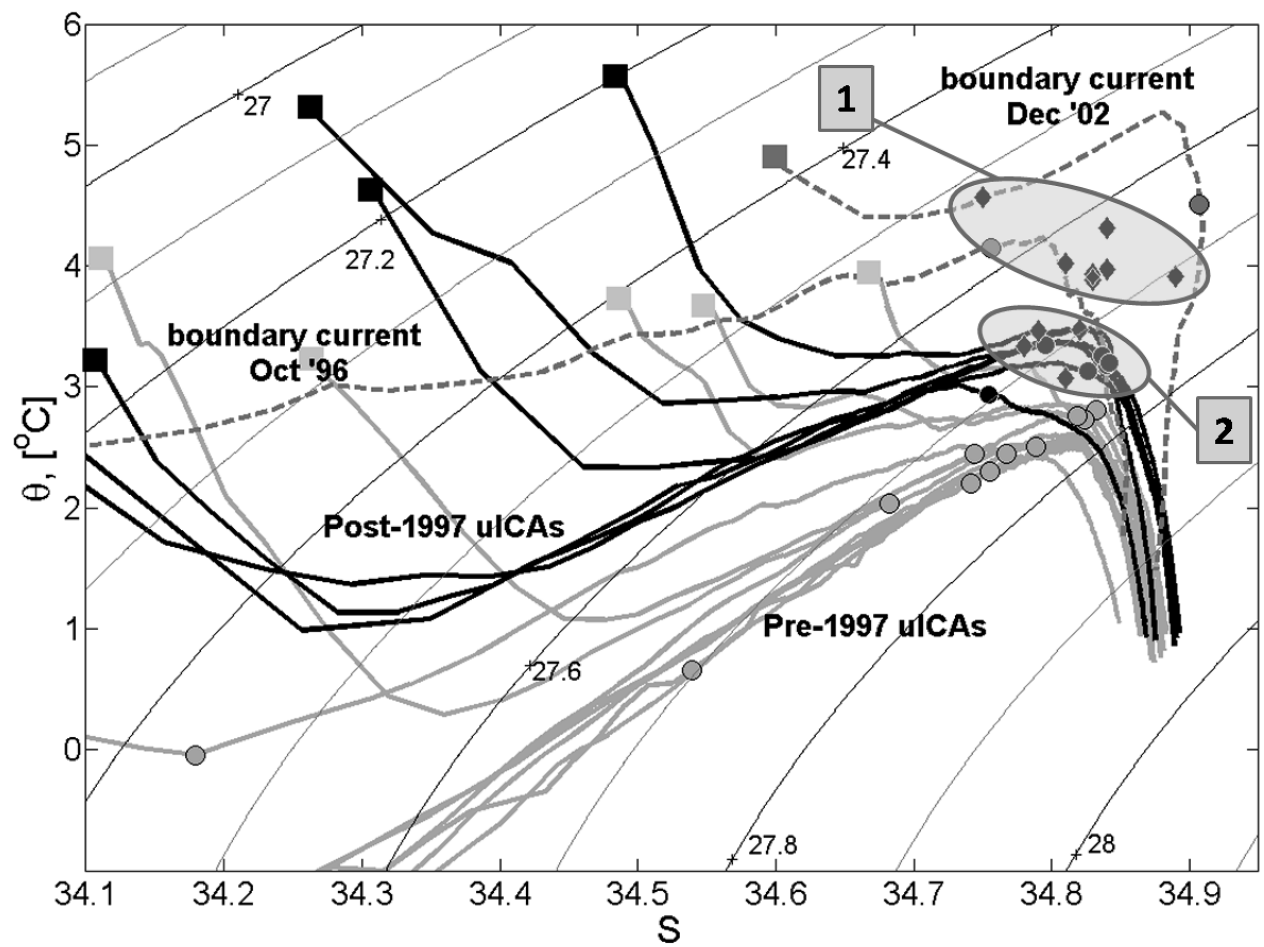

Figure 8. Unconvected pre-97 (light gray), post-97 (black) ICA and boundary current (dark gray dashed) mixed layer evolution trajectories. Diamonds show the properties of observed mixed layers in cICAs while the circles on each trajectory indicated the estimated mixed layer properties given a realistic buoyancy loss (see text). The squares mark the surface initial conditions for each profile. The shaded ellipses indicated the two clusters of cICAs described in the text.

coefficients are allowed to vary as functions of potential temperature and pressure. The surface buoyancy loss over the Labrador Sea, in the winter, is due both to cooling and evaporation. In analyzing the relative importance of either term, from wintertime shipbased observations from the Labrador Sea, L03 found, however, that their ratio is approximately constant. Thus, if one knows the buoyancy and this ratio one approximately also knows how much freshwater was evaporated and how much heat was removed (see L03, Appendix B for a more in depth discussion of the model and its assumptions for the Labrador Sea). Using the uICA as the initial (pre-convection) profiles and $\gamma$, the ratio of the evaporation to the heat flux, one can then estimate the time-varying evolution of the mixed layer and its properties.

The mixed layer evolution for all the sampled uICAs are plotted in $\theta / S$ space in Figure 8, together with those of two boundary current profiles from the west Greenland side taken during the fall. We stress that the trajectories represent the progressive change in mixed layer properties as the mixed layer deepens and should not be confused with the typical $\theta / S$ 
curves associated with a single hydrographic profile. The initial point of the mixed layer trajectory (indicated by a square) corresponds to the surface properties of the initial profile. The overall similar shape of the trajectories is due to the fact that the water mass structure in the profiles is qualitatively the same. The different slopes of the curves can be understood by considering that the surface layer of the uICAs is fresh and typically warm. Initially, evaporation and heat loss will result in a rapid cooling and, also, in an increase in salinity. As the buoyancy loss continues the mixed layer deepens into the warm, salty subsurface Irminger Water and the mixed layer becomes progressively warmer and saltier (even though the water column has undergone a net heat loss). As the mixed layer deepens beyond the Irminger Water, the mixed layer properties rapidly become colder again-due to the presence of the colder LSW beneath (Fig. 8). As evident from these curves, the trajectories associated with the pre-1997 uICAs and the post-1997 uICAs are quite different. After 1997, the mixed layer properties are systematically saltier and warmer.

Each point on the UICAs mixed layer properties' trajectories corresponds to a given buoyancy loss. On these curves we provide a more quantitative estimate of the mixed layer properties one would expect given a realistic buoyancy loss. This buoyancy loss is estimated using the climatological (annual) buoyancy loss curve derived by Straneo (2006a) from National Centers for Environmental Prediction (NCEP) reanalysis data. Explicitly, if the uICA is observed in October, for example, we calculate the net buoyancy loss it would experience from October to April (the end of winter) from the climatological flux curve and identify the mixed layer properties associated with this buoyancy loss. The mixed layer properties thus estimated are superimposed on the trajectories for each uICAs (and for two boundary current profiles), Figure 8. From the pre/post 1997 division it is apparent that mixed layer properties prior to 1997 are associated with larger densities $\left(>27.73 \mathrm{~kg} \mathrm{~m}^{-3}\right)$ than those after 1997 . The fact that these densities are greater than those of the Irminger Water suggests that convection would have penetrated beyond the Irminger Water layer in these eddies. By erasing the Irminger Water anomaly within the eddy, convection would effectively tend to erode the bulk of the eddy. While we can only speculate at this point-we note that this is consistent with our not finding any cICAs prior to 1997 and suggests that convection may have resulted in their destruction.

The estimated mixed layer properties for the uICAs are compared to those actually observed in the cICAs (in the case of the multiple mixed layers we show the upper one). The observed mixed layer properties fall into two clusters: cluster 1, centered on $\sigma=$ $27.65 \mathrm{~kg} \mathrm{~m}^{-3}\left(\theta \sim 4{ }^{\circ} \mathrm{C}\right)$ and relatively warmer and saltier than cluster 2 centered on $\sigma=$ $27.7 \mathrm{~kg} \mathrm{~m}^{-3}\left(\theta \sim 3{ }^{\circ} \mathrm{C}\right)$, Figure 8 . Of the two, mixed layers in cluster 2 roughly coincide with those estimated for the end of winter post-1997 uICAs. This supports the idea that cICAs from cluster 2 represent convectively modified uICAs formed after 1997. Mixed layers in cICAs from cluster 1, on the other hand, roughly fall in-between the mixed layer trajectories derived for the post-1997 uICAs and the boundary current's mixed layer 
trajectories. This suggests that, prior to undergoing convection, these eddies' properties were closer to those of the boundary current than the observed uICAs. While we have no direct evidence of it, we can think of several (related) scenarios in which this may happen:

The uICA profiles (post-1997) used to initialize the model were mostly observed in late/spring summer and, since they are unconvected, they are all likely to have formed towards the end of the winter/early spring. It is conceivable, therefore, that ICAs formed at a later time may have slightly different properties which, due to our biased sampling, we did not observe.

Mixed layer deepening may, in part, have occurred within the boundary current, prior to eddy formation, thus trapping some modified boundary current water.

In summary, this analysis supports the notion that

i) cICAs are effectively ICAs which have undergone wintertime convection and, therefore, that ICAs can indeed survive convection driven by the Labrador Sea's wintertime fluxes.

ii) The fresh cap at the surface of the ICAs is eroded through vertical mixing with the deeper, saltier IW, within the ICA itself.

iii) Wintertime convection can, and indeed often does, reach the Irminger Water layer and thus directly extract heat from this anomalously warm layer within the eddy.

iv) Convection in uICAs prior to 1997 would have likely led to the complete erosion of the Irminger Water anomaly which perhaps explains the absence of the cICAs before 1997. (We note, however, that our criteria for eddy identification rely on the existence of the IW core, hence we have no way of identifying ICAs in which convection has eroded or greatly modified this layer. The extent to which such eddies can survive convection beyond the IW layer thus remains an open question.)

We stress that we have no evidence that any of the uICA or cICA profiles belong to the same eddy. Indeed, we believe this is overall quite unlikely. Our assumption here, however, is that ICAs form with relatively similar conditions within a specific season of a specific year. Still caution must be taken in interpreting these results since the seasonality of either the boundary current or the ICAs properties is presently unknown. Another uncertainty of these experiments lies in the parameter $\gamma$ used in the model to define the ratio of the water column evaporation-precipitation fluxes to the heat fluxes. We found that our results are not very sensitive to its changes; however, if the mixed layer develops to significant depths, the slope of the evolution curve is different with variations of $\gamma$. Finally, the heat fluxes from NCEP obtained from Straneo (2006a) used in the experiments were reconstructed for the central Labrador Sea. To keep the calculations as simple as possible we have ignored the large interannual and spatial variability over the region (Straneo, 2006a). 


\section{Interannual variations of the ICAs}

The central Labrador Sea exhibits a large degree of interannual variability which, in turn, is associated with varying amounts and properties of LSW formed (Yashayaev, 2007b). While much of this variability has been attributed to the surface fluxes (Dickson $e t$ al., 2002) - these alone cannot explain all of the observed variability (L03; Straneo, 2006a). A second possible source of variability involves the exchange of heat and freshwater with the boundary current-an exchange primarily carried out by mesoscale eddies. Changes in the lateral fluxes may result from upstream changes in the boundary current's properties, such as the warming and increase in salinity reported by Myers et al. (2007), and/or from changes in the processes that induce boundary current instabilities (for example changes in the local or remote wind-stress) as manifested by the changes in the eddy kinetic energy off the west Greenland coast reported by Brandt et al. (2004). In both cases, such changes will likely be associated with changes in the number and characteristics of eddies and ICAs, in particular.

The connection between changes in ICAs and changes in the Labrador Sea's interior has been proposed by several investigators to explain the warming observed in 1997. This warming is attributed to an increase in the lateral heat fluxes (Straneo, 2006a) and coincides with an increase in the number of eddies observed as well as changes in their properties (L03). The mechanisms behind this change are unclear but it is known that 1997 was a transition year for the Labrador Sea region. Specifically, the North Atlantic Oscillation (NAO), the dominant mode of interannual variability over the North Atlantic, switched from a positive to a negative phase (Hurrell et al., 2001) which set an end to the extreme surface buoyancy loss (and convective activity) in the Labrador Sea that had persisted from the late 1980s to the early 1990s (Pickart et al. 2002; Lazier et al., 2002).

Here we investigate the potential role that ICAs play in influencing the Labrador Sea's properties by mapping changes in the ICAs characteristics and properties (both in the absolute sense and relative to the Labrador Sea's interior) over the period 1990-2004. It is noted that to quantify the lateral heat flux associated with the ICAs one would need to know both the number of eddies formed each year as well as their heat anomaly with respect to the interior. Since neither the satellite nor the hydrographic data can provide us with this information, we instead confine our analysis to a more qualitative discussion of the heat and freshwater content variability observed in the eddies.

\section{a. Water mass property variability}

As described above, 1997 was a year of transition for the Labrador Sea and the subpolar region, in general. Given that ICAs link the boundary current and the interior region, it is not surprising that they too exhibited a marked transition at this time. In this analysis, no convected ICAs were observed prior to 1997. While data coverage does not allow us to conclude that cICAs were not present prior to 1997 , it is reasonable to speculate that during the strongly forced earlier period these eddies may have been destroyed by convection during the winter. Indeed, the one-dimensional mixing model presented earlier suggests 


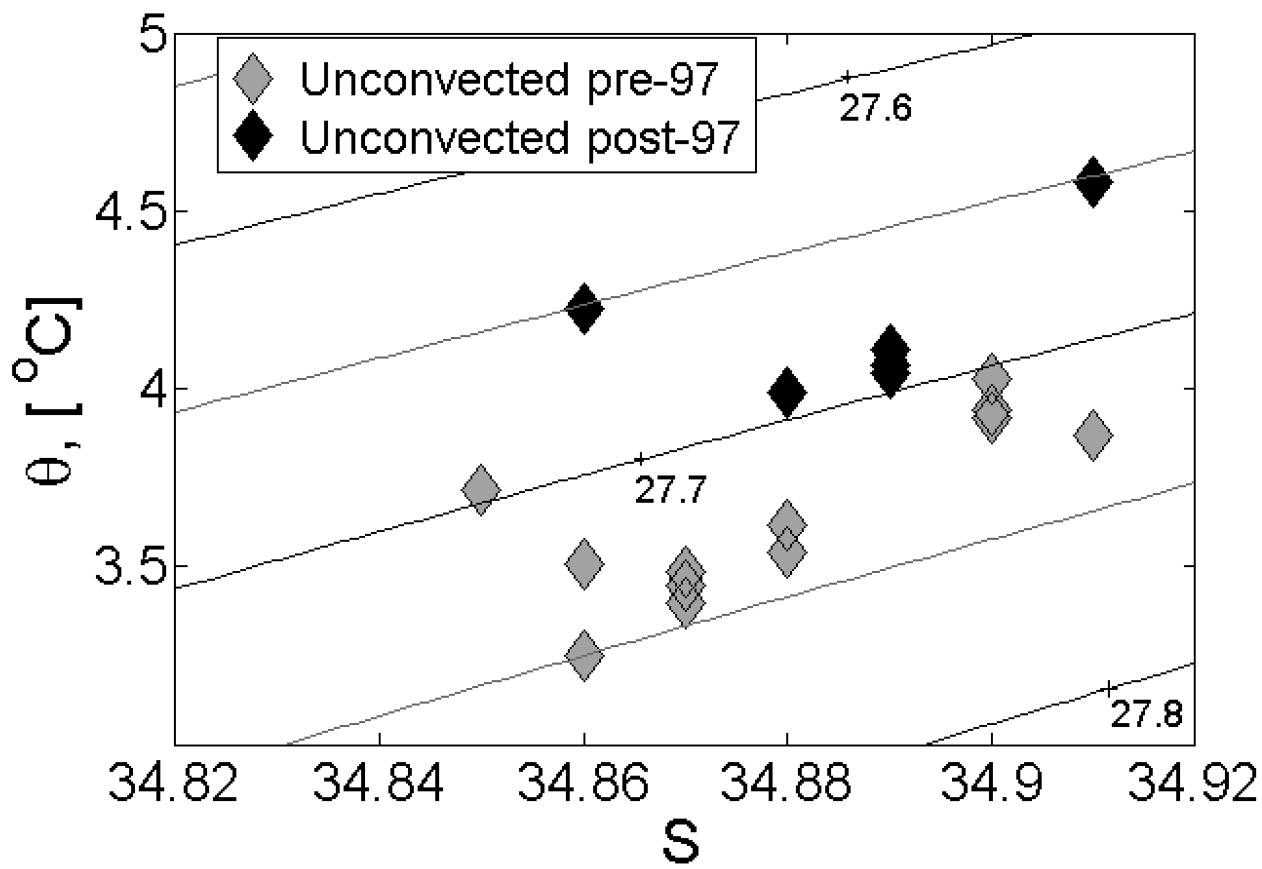

Figure 9. $\theta / S$ diagram showing the core properties of the unconvected ICAs. Color shows the time of observation: pre-1997 (gray) and in 1997 and after (black).

that convection would have penetrated beyond the Irminger Water layer in the pre-1997 uICAs.

Within uICAs, the layer from 200 to $1500 \mathrm{~m}$ is warmer, saltier and lighter following 1997 (Figs. 9 and 10). Note that this change is not restricted to the Irminger layer alone. It also appears that the post-1997 eddies are warmer in the upper $200 \mathrm{~m}$ however, considering
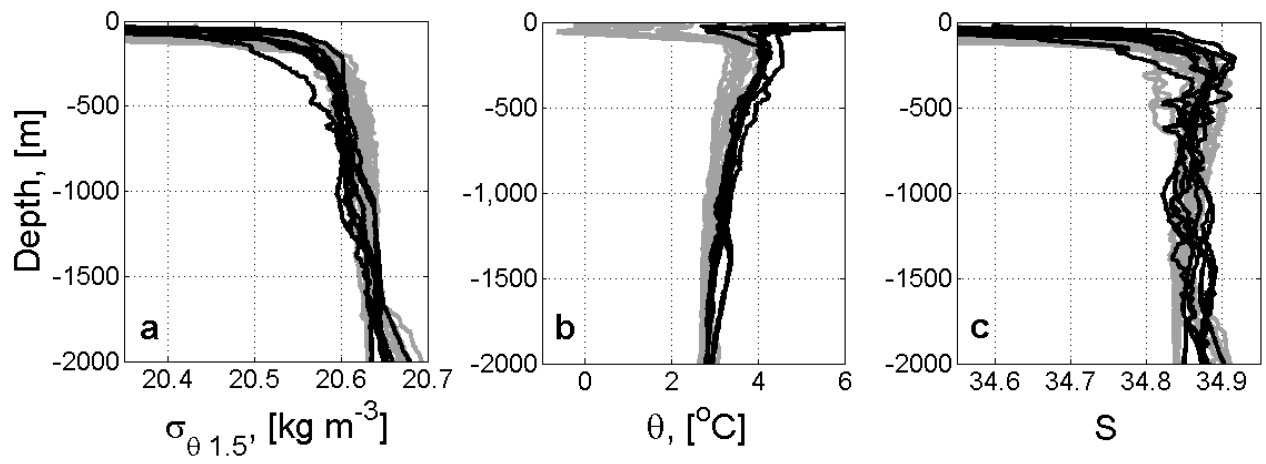

Figure 10. Unconvected ICAs observed pre-1997 (gray) and post-1997 (black): (a) potential density referenced to $1500 \mathrm{~m}$; (b) potential temperature; (c) salinity. 


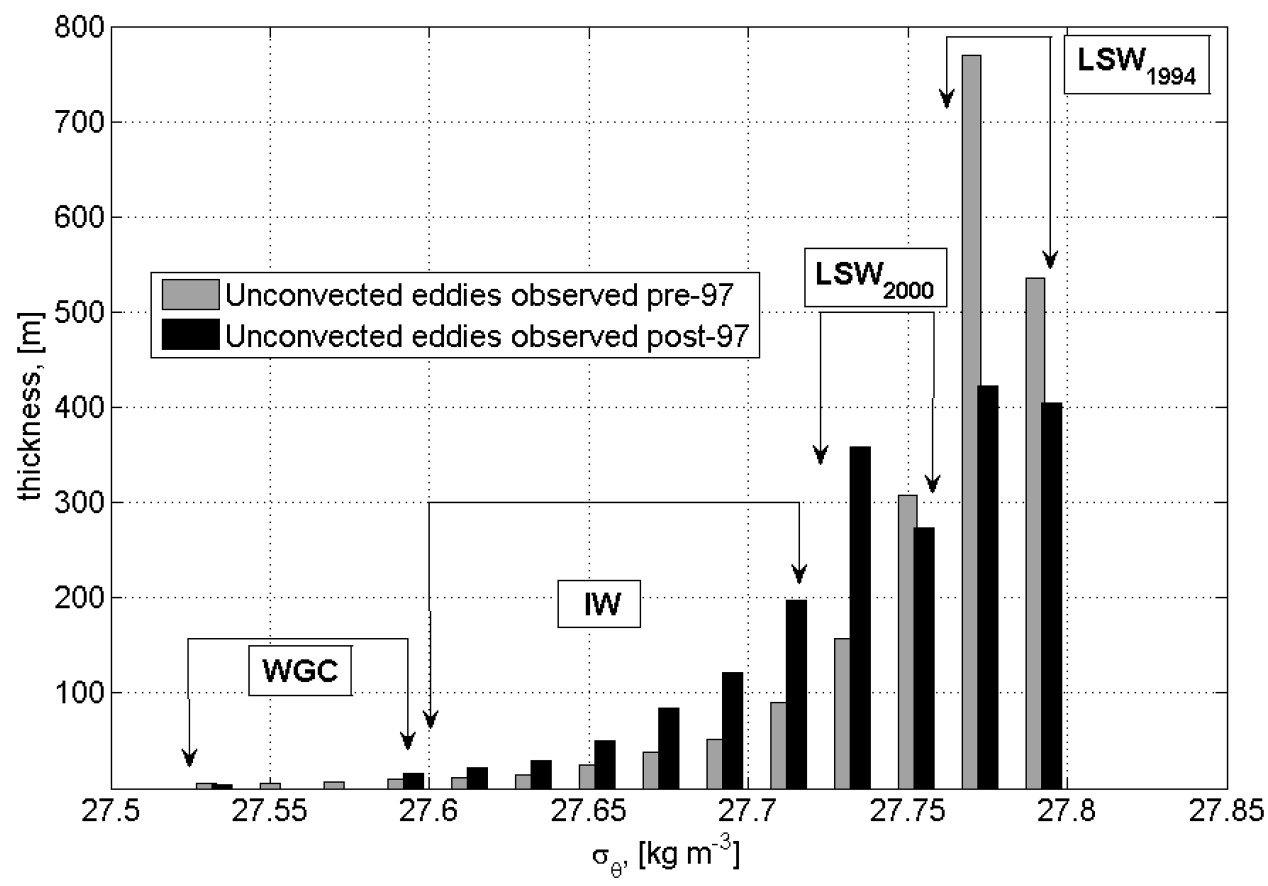

Figure 11. Layers' thickness in the unconvected ICAs (gray—pre-1997 and black—post-1997). The principal water masses and their density ranges are labeled.

the large seasonal variability in this upper layer, it is difficult to assess if this is a true interannual signal or a result of limited data points.

The shift from strong to weak convection that occurred in 1997 in the Labrador Sea was associated with the formation of lighter vintage of Labrador Sea Water $\left(\mathrm{LSW}_{2000}\right)$ than had been formed in earlier years ( $\mathrm{LSW}_{1994}$; Yashayaev, 2007a; Lazier et al., 2002). Following this change, the deep, older LSW layer progressively shrunk while the lighter, newer LSW layer thickened. Here, we show that a similar transition was going on at depth even within the eddies. The mean thickness of each relevant density class in the unconvected pre-1997 and post-1997 eddies is shown in Figure 11. Thickness is defined as the vertical spacing between the isopycnals corresponding to each of the water masses: $\sigma_{\theta}>27.76 \mathrm{~kg} \mathrm{~m}^{-3}$ and down to $2000 \mathrm{~m}$ for $\mathrm{LSW}_{1994} ; 27.76 \mathrm{~kg} \mathrm{~m}^{-3}>\sigma_{\theta}>27.72 \mathrm{~kg} \mathrm{~m}^{-3}$ for $\mathrm{LSW}_{2000}$; $27.6 \mathrm{~kg} \mathrm{~m}^{-3}<\sigma_{\theta}<27.72 \mathrm{~kg} \mathrm{~m}^{-3}$ for IW; from the surface to $\sigma_{\theta}<27.6 \mathrm{~kg} \mathrm{~m}^{-3}$ for the WGC. Similarly to the interior, the total LSW layer has decreased in thickness (from $88 \%$ to $74 \%$ ), with a decrease in the denser LSW and an increase in the lighter, while the IW layer has grown (from $11 \%$ to $25 \%$ ) at the expense of LSW.

In summary, we have observed that ICAs changed significantly around 1997 and, specifically, that they have become warmer and more buoyant as the Irminger Water layer has thickened at the expense of the LSW layer. In addition, the amount of $\mathrm{LSW}_{1994}$ has 
decreased yielding to the newly formed LSW. These changes are in line with those observed for the interior but had not, to our knowledge, been documented in detail for the eddies. In particular our analysis shows that the anomalies previously reported for 1997 appear to be associated with a shift in eddy properties which persisted past 1997. This finding is in agreement with the trends observed in the Irminger Current along the west Greenland coast, Myers et al. (2007).

\section{b. Heat and freshwater anomaly variability}

ICAs are warmer, saltier and more buoyant than the interior of the Labrador Sea and as such provide a net heat (and salt) flux to the interior (L03; H07; Straneo, 2006a). The magnitude of this flux, amongst other things, is proportional to the heat and freshwater anomaly contained within the eddy with respect to the interior. Here we estimate the interior-eddy heat and freshwater anomaly of uICAs (since no cICAs are observed prior to 1997) during the period 1990-2004.

For heat, we compare the heat contained in the upper $2000 \mathrm{~m}$ of an "interior water column" with an "eddy water column" as follows. The heat content, $\mathrm{HC}$, of a generic water column is defined as: $H C=\rho_{0} c_{p} \int_{-2000}^{0} \theta(z) d z$, where $\rho_{0}$ is the reference density $\left(\rho_{0}=\right.$ $\left.1027 \mathrm{~kg} \mathrm{~m}^{-3}\right) ; c_{p}$ is the heat capacity of water at constant pressure $\left(c_{p}=4200 \mathrm{~J}\right.$ $\left.\left(\mathrm{kg}^{\circ} \mathrm{C}\right)^{-1}\right)$. For the interior, the heat content is calculated using the horizontally averaged interior profile (eddies removed). Winter sections are omitted, for the sake of a better comparison with the uICAs since these are never observed in winter. For the eddies-we simply calculate the heat content of the eddy profile. As expected, the heat content of the eddies is always larger than that of the interior (Fig. 12). Both the interior and the eddy heat content increase from 1990 to 2004 — with the largest increase concentrated around 1997 (Fig. 12). While there is considerable scatter, the warming trend in both the ICAs and the interior is comparable, i.e. the heat content anomaly remains relatively constant in time. Thus, in an absolute sense, the net advection of heat into the interior due to a single eddy is relatively uniform in time. It is important to note, however, that the warming of the interior and of the eddy is occurring in different layers. The eddies are primarily warming in the upper layers while the interior is primarily warming in the deeper layers.

Finally, we investigate changes in the freshwater content of both the eddies and the Labrador Sea's interior. We define the freshwater content as:

$$
\Delta F W=h\left(\frac{S_{0}}{S_{n}}-1\right),
$$

where $\Delta F W$ is the amount of freshwater which must be added to an eddy (interior) profile from 1990 (the starting year) to match the vertically averaged salinity (again over $2000 \mathrm{~m}$ ) observed in the eddy (interior) for a given year; $h$ is a thickness of the layer considered; $S_{0}$ is the vertically averaged salinity of the 1990 eddy (mean); $S_{n}$ is the vertically averaged salinity of the given eddy (mean) profile. We find that both the interior and the eddies are becoming saltier (not shown). The observed increase in salinity of the interior is consistent 


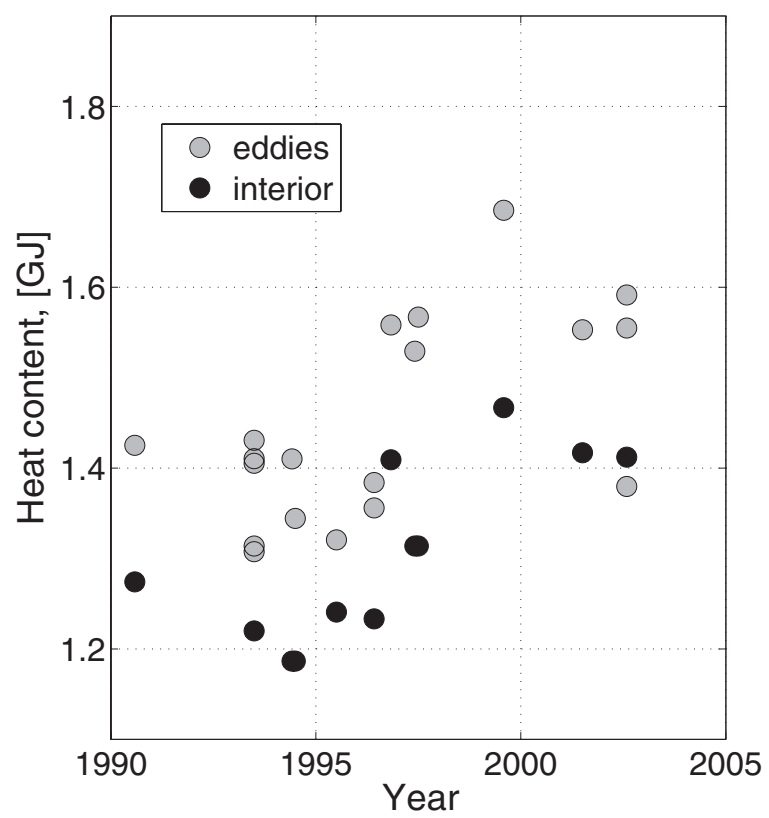

Figure 12. Heat content as a function of time in the interior and in the ICAs.

with that described in Straneo (2006a) and Yashayaev (2007a). The eddies, which are becoming saltier at a faster rate than the interior, owe their salinity increase primarily to the 200-800 m layer, i.e. the Irminger Water layer.

\section{Summary and discussion}

The annual cycle of convection and restratification of the Labrador Sea involves a vigorous exchange between the interior deep convective region and boundary currents which encircle the basin. This exchange, primarily achieved through mesoscale eddies that form as a result of boundary current instabilities, is a dominant player in the advection of heat into the interior necessary to balance the annual loss to the atmosphere. Also, it acts to modulate convection by controlling the degree of restratification that sets the stage for the following winter's convection. Of the many eddy-types present in the Labrador, one particular kind - the Irminger Current Anticyclones-is thought to dominate the interior/boundary current exchange. Indeed, previous studies suggest that these eddies alone supply up to $90 \%$ of the heat and $50 \%$ of the surface freshwater that seasonally re-stratifies the basin. These eddies are formed by a topography-induced instability of the boundary current system off of the west Greenland coast. They effectively trap and carry warm, salty water of subtropical origin, Irminger Water, into the Labrador Sea and, perhaps also the fresh surface waters of polar origin.

Notwithstanding their importance for the annual budgets, little is known about how, where and when these eddies release their anomalous heat and salt contents into the 
Labrador Sea's interior. This is an important question as we try to understand how this convective basin seasonally re-stratifies and what processes govern its interannual variability. In particular, can these eddies survive the large winter heat loss of the Labrador Sea? What controls their variability (in number and properties) and how does it relate to that observed in the Labrador Sea?

In this study we compiled a database of in situ eddy observations by identifying 29 ICAs over 15 years of hydrographic data (from 1990-2004). We found that the ICAs naturally fall into two categories, based on their water mass properties and vertical structure: unconvected eddies and convected eddies. The former have a fresh surface layer above the subsurface warm Irminger Water-resembling the stacking of water masses in the boundary current. While two ICAs with a fresh cap had been previously reported, these were located in the boundary current itself; here we document eddies with a fresh cap in basin's interior as well. The convected eddies have at least one mixed layer, whose thickness range from 100 to $800 \mathrm{~m}$. These do not have a fresh surface layer and contain a colder, fresher modified Irminger Water layer.

Generally speaking, unconvected eddies were observed in the proximity of the boundary currents along the Greenland and the Labrador coasts. This is consistent with the existence of two distinct eddy pathways: one from the region of formation (along the Greenland coast) straight into the Labrador Sea's interior and the second around the boundary current, to the Labrador coast, and only then into the Labrador Sea's interior. Eddies associated with the latter pathway appear to have the freshest surface cap which may indicate that they are the youngest ICAs observed. This finding suggests that eddies are an efficient way of preserving and carrying fresh surface and subsurface warm/salty anomalies from the coast of Greenland into the Labrador Sea's interior through multiple pathways.

Through the analysis of the water properties and using a one-dimensional mixing model, it is argued that convected eddies are eddies that have undergone vertical convective mixing during the Labrador Sea's intense winter. This suggests that (1) these eddies can survive, and remain coherent, while undergoing strong water mass transformation and (2) that their exchange with the surrounding water is limited. This is consistent with the numerical simulations of Legg and McWilliams (2001) who found that when a large surface buoyancy loss is applied to a field of baroclinic cyclones and anticyclones, the latter tend to survive while the former tend to be destroyed. The survival of the buoyant anticyclones to the wintertime surface buoyancy loss, in turn, has several important implications for when and where the anomalous heat and salt of the eddy are released.

First, winter convection mixes the surface fresh layer into the underlying Irminger Water thus partially neutralizing the eddy's salinity anomaly with respect to the surroundings. Thus, it seems unlikely that these eddies may contribute to the seasonal freshwater restratification of the surface layer, known to occur in the spring, if their fresh layer is effectively removed in the winter. Second, the eddy's anomalous heat content can be directly removed by the atmospheric heat loss without being first mixed into the surrounding interior waters. 
A clear change in eddy properties occurred following the winter of 1996-1997 when the Labrador Sea switched from a strongly convecting decade to a weakly convecting decade. Specifically, no convected eddies were found prior to 1997, and post-1997 unconvected eddies contain a thicker, warmer, more buoyant layer of Irminger Water. The heat content increase observed in the eddies is occurring at the same rate as that observed in the Labrador Sea's interior. It is speculated here that changes in the eddies are indicative of changes that are occurring over the larger scale of the subpolar gyre. In particular, it is likely that no convected eddies were observed during the strong convection period since they may have been destroyed by the large surface fluxes. Furthermore, the changes in the eddies are consistent with those reported in the boundary currents around the basin.

Acknowledgments. The authors would like to thank all of the PIs who collected the hydrographic data which was used in this study, especially given the harsh conditions often encountered in the Labrador Sea. A. Bower contributed many useful discussions during the analysis. Comments from two anonymous reviewers helped improve the manuscript. The work was funded by National Science Foundation grant number OCE-0525929.

\section{REFERENCES}

Bracco, A., J. Pedlosky and R. Pickart. 2008. Eddy formation near the west coast of Greenland. J. Phys. Oceanogr., 38, 1992-2002.

Brandt, P., F. Schott, A. Funk and C. Sena Martins. 2004. Seasonal to interannual variability of the eddy field in the Labrador Sea from satellite altimetry. J. Geophys. Res., 109, C02028, doi:10.1029/ 2002JC001551

Cuny, J., P. B. Rhines, P. P. Niiler and S. Bacon. 2002. Labrador Sea boundary currents and the fate of the Irminger Sea Water. J. Phys. Oceanogr., 32, 627-647.

Curry, R., M. McCartney and T. Joyce. 1998. Linking subtropical deep water climate signals to North Atlantic subpolar convection variability. Nature, 391, 575-577.

Dickson, R., B. Rudels, S. Dye, M. Karcher, J. Meincke and I. Yashayaev. 2007. Current estimates of freshwater flux through Arctic and subarctic seas. Prog. Oceanogr., 73, 210-230.

Dickson, R. R., J. R. N. Lazier, J. Maincke, P. B. Rhines, and J. Swift. 1996. Long-term coordinated changes in the convective activity of the North Atlantic. Prog. Oceanogr., 38, 241-295.

Dickson, R., I. Yashayaev, J. Meincke, B. Turrell, S. Dye and J. Holfort. 2002. Rapid freshening of the deep North Atlantic over the past four decades. Nature, 416, 832-837.

Eden, C. and C. Böning. 2002. Sources of eddy kinetic energy in the Labrador Sea. J. Phys. Oceanogr., 32, 3346-3363.

Haine, T., C. Böning, P. Brandt, J. Fischer, A. Funk, D. Kieke, E. Kvalebers, M. Rhein and Martin Visbeck. 2007. North Atlantic Deep Water formation in the Labrador Sea recirculation through the Subpolar Gyre, and discharge to the subtropics, in Arctic-Subarctic Ocean Fluxes, R. Dickson, J. Meincke and P. Rhines, eds., Springer, 653-702.

Harcourt, R., E. Steffen, R. Garwood and E. D'Asaro. 2002. Fully Lagrangian floats in Labrador Sea deep convection: comparison of numerical and experimental results, J. Phys. Oceanogr., 32, 493-510.

Hatun, H., C. C. Eriksen and P. B. Rhines. 2007. Buoyant eddies entering the Labrador Sea observed with gliders and altimetry. J. Phys. Oceanogr., 37, 2838-2854.

Hurrell, J. W., Y. Kushnir and M. Visbeck. 2001. Climate. The North Atlantic oscillation. Science, $\underline{26,603-605 .}$

Katsman, C., M. A. Spall and R. S. Pickart. 2004. Boundary current eddies and their role in the restratification of the Labrador Sea. J. Phys. Oceanogr., 34, 1967-1983. 
LSDCE, The Lab Sea Group. 1998. The Labrador Sea deep convection experiment. Bull. Amer. Meteor. Soc., 79, 2033-2058.

Lavender, K., R. Davis and W. Owens. 2000. Mid-depth recirculation observed in the interior Labrador and Irminger seas by direct velocity measurement. Nature, 407, 66-69.

Lavender, K, W. B. Owens and R. E. Davis. 2005. The mid-depth circulation of the subpolar North Atlantic Ocean as measured by subsurface floats. Deep-Sea Res. I, 52, 767-785.

Lazier, J. 1980. Oceanic conditions at ocean weather ship Bravo; 1964-1974. Atmos. Ocean, 18, 227-238.

Lazier, J. R. N., A. Clarke, I. Yashayaev and P. B. Rhines. 2002. Convection and restratification in the Labrador Sea, 1990-2000. Deep-Sea Res., 49, 1819-1835.

Legg, S. and J. C. McWilliams, 2001. Convective modifications of a geostrophic eddy field. J. Phys. Oceanogr., 31, 874-891.

Lilly, J. M., P. B. Rhines, M. Visbeck, R. Davis, J. R. N. Lazier, F. Schott and D. Farmer. 1999. Observing deep convection in the Labrador Sea during winter 1994/95. J. Phys. Oceanogr., 29, 2065-2098.

Lilly, J. M. and P. B. Rhines. 2002. Coherent eddies in the Labrador Sea observed from a mooring. J. Phys. Oceanogr., 32, 585-598.

Lilly, J. M., P. B. Rhines, F. Schott, K. Lavender, J. R. N. Lazier, U. Send, and E. D’ Asaro. 2003. Observations of the Labrador Sea eddy field. Prog. Oceanogr., 59, 75-176.

Marshall, J. and F. Schott. 1999. Open-ocean convection: observations, theory, models. Rev. Geophys., 37, 1-64.

Myers, P. G., Kulan, N. and M. H. Ribergaard. 2007. Irminger Water variability in the West Greenland Current. Geophys. Res. Lett., 34, (L17601), doi:10.1029/2007GL030419.

Pickart, R. S. and M. A. Spall. 2007. Impact of Labrador Sea convection on the North Atlantic meridional overturning circulation. J. Phys. Oceanogr., 37, 2207-2227.

Pickart, R. S., D. J. Torres and R. A. Clarke. 2002. Hydrography of the Labrador Sea during active convection. J. Phys. Oceanogr., 32, 428-457.

Prater, M. D. 2002. Eddies in the Labrador Sea as observed by profiling RAFOS floats and remote sensing. J. Phys. Oceanogr., 32, 411-427.

Rhein M., D. Kieke and R. Steinfeldt. 2007. Ventilation of the upper Labrador Sea Water, 2003-2005. Geophys. Res. Lett., 34, (L06603), doi:10.1029/2006GL028540.

Schmidt, S. and U. Send. 2007. Origin and composition of seasonal Labrador Sea freshwater. J. Phys. Oceanogr., 37, 1445-1454.

Spall, M. A. 2004. Boundary currents and water mass transformation in marginal seas. J. Phys. Oceanogr., 34, 1197-1213.

Straneo F., R. S. Pickart and K. Lavender. 2003. Spreading of Labrador Sea Water: an advectivediffusive modeling study based on Lagrangian observations. Deep-Sea Res. I, 50, 701-719.

Straneo, F. 2006a. Heat and freshwater transport through the central Labrador Sea. J. Phys. Oceanogr., 36, 606-628.

2006b. On the connection between dense water formation, overturning, and poleward heat transport in a convective basin. J. Phys. Oceanogr., 36, 1822-1840.

Yashayaev, I. 2007a. Changing freshwater content: insights from the subpolar North Atlantic and new oceanographic challenges. Prog. Oceanogr., 73, 203-209.

- 2007b. Hydrographic changes in the Labrador Sea, 1960-2005. Progr. Oceanogr., 73, 242-276.

Yashayaev, I., J. R. N. Lazier and R. A. Clarke. 2003. Temperature and Salinity in the Central Labrador Sea, ICES Marine Symposia Series, 219, 32-39. 